\title{
Study on the Long-term Mechanism of Energy-saving Technology Promotion about Rural Residences in Hot Summer and Cold Winter Zone
}

\author{
Mingqiang Huang, Jinheng Li ,Cunyuan Wang \\ School of Civil Engineering \& Architecture, Xiamen University of Technology, \\ Xiamen, 361024, China. \\ hmq6888717@163.com
}

\begin{abstract}
Keywords: rural residences, hot summer and cold winter, energy-saving technology, long-term mechanism

Abstract. Reducing the energy consumption of villages and towns and raising their energy efficiency is one of the priorities for the development of sustainable buildings in China. This article takes the village and township houses in hot summer and cold winter zone as the research object. Based on the analysis of the climatic characteristics and energy consumption characteristics, the paper discusses the popularization of long-term mechanism for appropriate energy-saving technologies in villages and towns in hot summer and cold winter zone from the government, developers and village residents.
\end{abstract}

\section{Introduction}

Along with the promotion of sustainable development idea in recent years, the problems of energy crisis and environmental pollution have been attracting increasing attention in the world. What is more, the energy conservation and emission reduction also become a common development strategy and consensus around the world. Many related concepts, such as low-carbon economy, ecological city, green building and energy conservation building, have become the hot topics nowadays. As the pillar industry to promote the national economic development, the construction industry, with industrial energy consumption and transportation energy consumption, has become the three major energy consumers in our country. According to the 2017 China Building Energy Consumption Study Data showed that in 2015 China's building energy consumption was about 85.7 billion tons of standard coal, which accounted for $20 \%$ of the total energy consumption in China and the rural building energy consumption was about 197 million tons of standard coal. Thus, to reduce rural residences' energy consumption and to increase the energy utilization will be the top priority to develop sustainable architecture in China. Also, they will be a key link to promote constructing resources- conservation society in China. This paper will take rural house in hot summer and cold winter zone as the research object, based on the analysis of the characteristics of its climate, characteristics, etc, and on the basis of energy consumption, to discuss rural house in hot summer and cold winter zone suitable for energy saving technology to promote long-term mechanism.

\section{Climate Characteristics in hot summer and cold winter zone and its basic building requirements}

\section{District and climate type in hot summer and cold winter zone}

In order to facilitate the energy saving of residential buildings and improve the living environment, the Civil Building Thermal Design Code in China (GB50176-93) divides the nation's buildings into five climatic zones in accordance with the building thermal design requirements [1]. The design requirements for building thermal design in various districts and winter insulation of residential buildings in different areas and summer heat protection are proposed. And the main purpose is to gradually improve the quality of indoor thermal environment in residential buildings, reduce the energy consumption of buildings, and create a healthy and comfortable living environment. At the same time, it also provides a reliable basis for adopting appropriate building energy-saving technologies. 
According to China's thermal engineering design zoning, the hot summer and cold winter zone are located between the cold zone and the hot zone of China and belong to the transition zone. The region is the most densely populated region in China and has a relatively developed economy and culture. Its political and economic status is extremely important. Its climate is marked by its summer heat, cold winters, and high humidity throughout the year. Moreover, the climate in the region is poor and it is a region with poor weather conditions in the same latitudes in the world. The average temperature in the hottest months of the region is $25-30^{\circ} \mathrm{C}$, and is mostly $28-30^{\circ} \mathrm{C}$. The average temperature in July is $2^{\circ} \mathrm{C}$ higher than in other parts of the world at the same latitude. Due to the low latitude and continuous sunny days, the summer solar radiation is quite strong. There is also a "heat island" problem in major cities in this region. According to the different wind speed, wind direction, topography, building density and height, the temperature in the center of the city is generally $1-3{ }^{\circ} \mathrm{C}$ higher than the surrounding areas. Due to the very humid climate in this area, the relative humidity is often as high as $80 \%$. In the middle and lower reaches of the Yangtze River, although the temperature is not very high during the Huangmei season in the early summer, people feel very uncomfortable because of the low air pressure and high humidity.

The average temperature in the coldest months of the region is $2-7^{\circ} \mathrm{C}$, mostly between $2-5^{\circ} \mathrm{C}$. The average temperature in January is generally $8-10^{\circ} \mathrm{C}$ lower than in other parts of the world at the same latitude, and it is the coldest region in the world with the same latitude in winter. In the middle and lower reaches of the Yangtze River and in the area north of the Yangtze River, the number of days where the minimum daily temperature is below $5^{\circ} \mathrm{C}$ is up to two months, even to the nearest three months. The relative humidity in the area during the winter season is still very high, ranging from $73 \%$ to $83 \%$. The rain and snow throughout the winter so that the weather is cold and gloomy.

\section{The basic requirements of hot summer and cold winter building}

Due to the climatic features of the climatic region, the poor sealing of the windows of existing villages and towns and the low heat insulation of the roof, the requirements for the construction of the climatic zone are as follows: buildings should meet the requirements of heat insulation, sun shading in the summer, moisture protection in the rainy season, etc. In winter, attention must be paid to the requirements of cold and heat preservation. The overall planning, design and construction of the house should meet the requirements for heat insulation and shade that are too long for the summer sunshine. Pay attention to the orientation of the rooms and the spacing of the buildings to prevent typhoons and heavy rain in the summer. The building structure should consider the winter insulation and the moisture requirements of the summer rainy season.

\section{The Characteristics of Building's Energy Consumption in Hot Summer and Cold Winter Zone}

For further analysis, we chose 138 sets of traditional villages and towns in Zhangzhou, Quanzhou, Putian, Ningde, Longyan, and Nanping cities in Fujian Province; 62 sets of traditional villages and towns in Jingdezhen, Shangrao, and Jiujiang in Jiangxi Province; 31 sets of traditional villages and towns in Yiyang, Xiangtan and Zhuzhou in Hunan Province; 36 sets of traditional villages and towns in Huainan, Fuyang and Suzhou in Anhui Province as examples to analyze the energy consumption characteristics of buildings in rural residences from three aspects of the Enclosure structure, heating and ventilation, lighting design.

\section{Enclosure structure}

\section{Masonry thermal insulation}

The building's envelope structure has the outer guard structure and the inner guard structure. The maintenance structure considered in this article is the outer guard structure, which usually includes the roof, exterior wall, outer door and side window of the building. Its main purposes are to withstand the effects of wind and rain, heat insulation, fire resistance, moisture, and load-bearing. And in terms of energy-saving and emission reduction, we mainly consider the thermal insulation function of building enclosure structure. In the surveyed 267 sets of traditional residences, they were all designed by themselves and built with solid bricks, all of them are belonging to independent small houses. 
However, according to the statistical analysis of the survey report, 95.13\% of the thermal insulation measures of the enclosure structure were not achieved, and only $4.87 \%$ of the users took thermal insulation measures. The thermal insulation measures adopted are basically the method of sticking insulation films on windows in the summer and glass insulation films or brushing glass thermal insulation coatings on windows in winter. There are 3 households that install sealing strips on windows and doors. However, all the rural residences do not take thermal insulation measures on the external walls, and all the thickness of walls are $240 \mathrm{~mm}$, which is prone to thermal bridges.

\section{Roof insulation}

The main methods of roof insulation include external insulation, internal insulation, non-insulation, and strip vapor barrier. The results of statistical analysis are shown in Chart 1 . It can be seen from Chart 1 that: In the surveyed 267 sets of traditional houses, $92.13 \%$ of rural building roofs were not insulated, only $7.87 \%$ of rural residences used insulation measures. In rural residences where insulation measures were adopted, external insulation measures accounted for $2.25 \%$, strip vapor barrier measures accounted for $3 \%$, and the proportion of other methods is $1.31 \%$.

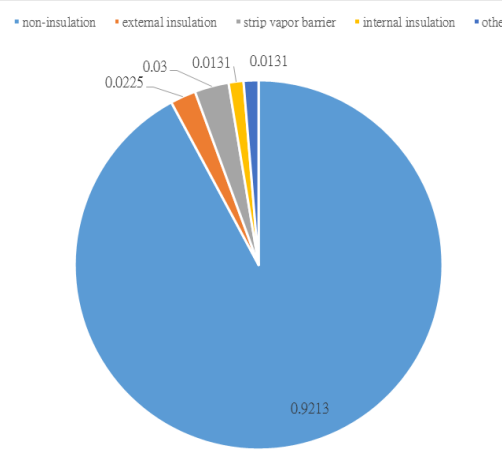

Chart 1: Statistical analysis of roof insulation

\section{Heating and ventilation \\ Winter heating measures}

In the hot summer and cold winter zone, the main heating measures in rural areas are the following types: residential-type centralized air-conditioning, split-type air-conditioning, central heating, gas heating stoves, electric heating, soil heating, fire pits, stoves or other methods. The statistical analysis results of the winter heating measures in the 267 sets of traditional houses surveyed are shown in Chart 2. Chart 2 shows that in the winter season, split-type air conditioners, stoves, and fire pits dominated the heating measures used in rural residences in hot summer and cold winter zone, and $32 \%$ of the users adopted a more primitive method: firewood heating, briquettes heating and coal heating, etc. These type of energy utilization are relatively low, but also pollute the environment, while the use of central heating, electric heating and gas heating furnace are very few.

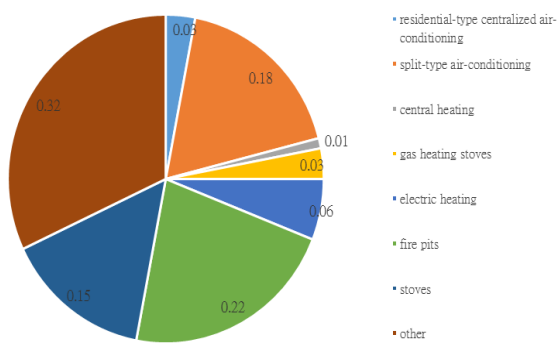

Chart 2 Statistical Analysis of Winter Heating Measures

\section{Summer cooling measures}

Summer cooling measures include the following several methods: residential-type centralized air-conditioning, split-type air-conditioning, air-conditioning fans, fans, no measures, split-type air-conditioning and fan combination, a total of six ways. The statistical analysis results of the winter heating measures in the 267 sets of traditional housing surveyed are shown in Chart 3 . As can be seen 
from Chart 3, 3\% of residents did not take any cooling measures, $45 \%$ used electric fans, 30\% used split-type air conditioners and fans, and 19\% used split air conditioners. Central air conditioning is rarely used. It can be seen that although the summer temperatures in hot summer and cold winter zone are relatively high, electric fans are mainly used in rural areas to cool down. The reason may be is the rural economic conditions in this region and few hot summer days in some provinces.

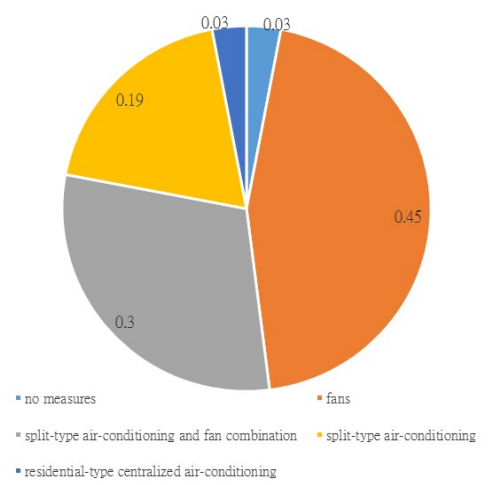

Chart 3 Statistical Analysis of Summer Cooling Measures

\section{Lighting Design}

In the surveyed 267 sets of traditional rural residences in hot summer and cold winter zone, $56 \%$ of fluorescent lamps are used as the main lighting source, and $23 \%$ of incandescent lamps are used as the main lighting source. $18 \%$ using a mixture of fluorescent and incandescent lamps as the lighting source, LED lighting as a light source accounted for 3\%, as shown in Chart 4 . It can be seen that people's requirements for the selection of electric light sources are continuously increasing, from the previous incandescent lamps to the soft fluorescent lamps, energy-saving lamps, and efficient light sources. Incandescent lamps will be gradually reduced in the well-off residences, although it has the advantages of low cost, easy installation, at the same power, it has low luminous efficiency and poor color. Fluorescent lamps are one of the most widely used products. Although the cost is higher, it has the advantages of beautiful appearance, good light source color, power saving, small size, and easy installation, and it will eventually replace incandescent lamps.

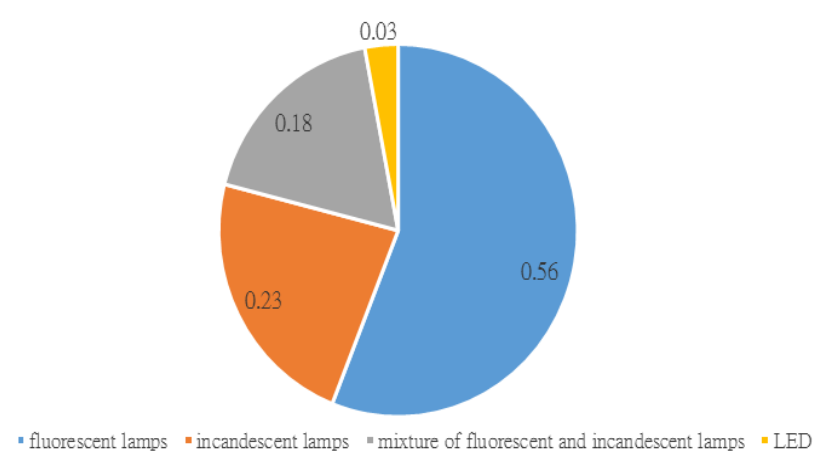

Chart 4 light source type

\section{Long-term Mechanism of Energy-saving Technology Promotion}

Increase the capital investment in the energy-saving construction of rural residences and expand the construction of demonstration sites

Funds are a key factor constraining the energy-saving construction of villages and towns. In order to speed up the development of energy-saving residential buildings in villages and towns, the government should increase the input of financial funds. Formulate economic incentive policies and related preferential policies such as fiscal and taxation subsidies for energy conservation construction for the use of energy-efficient residential buildings in villages and towns, for example, the research and development of energy-saving technologies, promotion of energy-saving concepts, application and promotion of energy-saving technologies, demonstration of energy-saving housing construction, 
etc. Funds for energy-saving construction of residential buildings in villages and towns, such as special funds for new energy research and development and special funds for energy-saving renovation of rural residential buildings. Financial institutions are encouraged to provide credit support to relevant units involved in the energy-saving construction of rural residences in order to obtain funds for investment in energy-saving projects. At the same time, new energy and biomass energy will be encouraged, such as solar energy, biogas digesters, sewage ecological ponds, geothermal energy, wind energy, etc. Moreover, in the entire country, the demonstration sites for energy-saving construction of rural residences will be expanded to increase their penetration rate.

Increase the propaganda of residential energy-saving construction in rural residences

Promoting energy-saving construction of residential houses in rural areas are an important part of China's implementation of energy conservation, protection of the ecological environment, implementation of relevant laws and regulations, and the realization of sustainable development and other basic national policies ${ }^{[2]}$. Strengthen the propaganda of residential energy-saving construction in villages and towns, increase the awareness of energy saving in residential buildings throughout the country, popularize the general knowledge of residential energy conservation, promote construction, design, construction, supervision, quality supervision, management, and residents need to understand and handle the energy-saving technologies of villages and towns as soon as possible. Create a good atmosphere for the energy-saving of residential buildings in the whole society and form consensus on consciously participating in and actively investing in residential energy conservation is the key to the comprehensive development of residential energy-saving in villages and towns ${ }^{[3]}$.

\section{Increase supervision}

The energy-saving construction of residential houses in villages and towns involves many parties. Coordinating them is a complex system. Each participant plays a game in the entire construction process, and both are pursuing the maximization of their own interests. Therefore, as an organizer, it is necessary to manage and supervise them. Each participating part can comply with the relevant laws and regulations, follow the relevant energy-saving construction standards of villages and towns, which can ensure the promotion of suitable energy-saving technologies for villages and towns and sustainable development of energy-saving construction of residential buildings in villages and towns.

\section{Developers actively adopt advanced energy-saving technologies to develop energy-saving} houses

The core of energy-saving residential construction in rural areas are to use appropriate energy-saving technologies to create a healthy and comfortable living environment for villages and towns, and to achieve the sustainable development of energy-saving construction of villages and towns. As a real estate developer, the main task is to effectively adopt appropriate energy-saving technologies for energy-saving construction during the construction process, and strictly follow the corresponding construction process flow to ensure the energy-saving insulation and energy saving effect.

\section{Actively change village residents' ideology}

The slow development of the energy-saving construction of residential buildings in villages and towns is affected not only by the climate, economic conditions, and politics of different regions, but also to a large extent by the customs, traditions, and culture of various places. Therefore, while actively promoting the energy-saving construction of villages and towns, it is also necessary for residents to actively change their ideological concepts, accept new things, and be able to carry out energy-saving transformation of existing residences in villages and towns, and even provide support for large-scale energy-saving construction. Residents must realized that the energy conservation construction of rural areas can not only promote the development of suitable energy-saving technologies, but also improve the living environment. 


\section{Conclusions}

With the release of the national economic incentive technology promotion policies and the acceleration of the urbanization process, the promotion of energy-saving technologies in the construction of rural houses has received increasing attention. Based on the analysis of the climate characteristics and energy consumption characteristics of hot summer and cold winter zone, from the national promotion of energy conservation technology and the implementation of energy conservation incentive policies, developers actively adopt advanced energy-saving technologies to the change of village residents' ideology, this article put forward the long-term mechanism of energy-saving technology promotion for rural areas, in order to facilitate the promotion of suitable energy-saving technologies in the construction of rural residences

\section{Acknowledgements}

This research was supported by the National Natural Science Foundation of China (NSFC) (Grant No.71503224) and Fujian Social Natural Science Foundation (Grant No. FJ2015C110). The work described in this paper was also funded by Fujian Province Middle and Young Teacher Education Research Program (Grant No. JA15374) ; the Program for High Level Talents in Xiamen University of Technology (Grant No. YKJ4024R)and University Outstanding Young Scientific Research Talent Cultivation Program Project in Fujian Province

\section{References}

[1] Long Weiding. Building energy efficiency and building energy efficiency management [M] China Building Industry Press, 2005,7

[2] Huang Mingqiang, Cui Shenghui, Li Xiufang. Analysis of structural equation model for influencing factors of popularization and application of building energy-saving products [J] Journal of Huaqiao University(Natural Science), 2016(4): 447-450

[3] Huang Mingqiang, Li Jinheng.Analysis on energy-saving path of rural buildings in hot summer and cold winter zone[J]Earth and Environmental Science,2018:1-5 